\title{
A Descriptive Study To Assess The Contributing Factors Of Infertility And Treatment Modalities Used Among The Infertility Couples
}

\author{
Uma Maheswari.R
}

\begin{abstract}
:
Objectives: To assess the contributing factors of infertility among the infertile couples attending Out Patient Department, to find out the availability of various type of treatment modalities among infertile couples Methods: Descriptive research design was adopted for the study. Result: The Study finding showed that $84 \%$ of the infertile couples comes under primary infertility. $74 \%$ of infertile couples adopted invitro fertilization. The Contributing factors of infertility among infertile couples were endocrine disorder (40\%), obstruction or absence of seminal duct (40\%). Conclusion: The study concluded that majority of the women were infertile than male. Infertility can be treated and cured and there is a great need to improve the awareness regarding the investigations and treatment modalities of infertility.
\end{abstract}

Keywords: Infertility, Contributing factors , Endocrine disorder

\section{INTRODUCTION}

Infertility is a global Phenomenon. Infertility is defined as a failure to conceive within one or more years of regular unprotected coitus. ${ }^{1}$ Generally ,Worldwide it is estimated that one in seven couples have problems in conceiving. Nearly $80 \%$ of couples achieve conception, if they so desire within 1 year of regular intercourse with adequate frequency. Another $10 \%$ will achievetheobjectivebytheendof2ndyear .About $10 \%$ remain infertility by the end of $3^{\text {rd }}$ year. ${ }^{5}$ The main causes of infertility in female factors were ovulatory dysfunction $40 \%$, tubal factors $40 \%$ uterine factors $10 \%$, cervical factors $5 \%$,Peritoneal factors $5 \%$ and other causes might be marital problems, Psychological factor, sexual factor, lack of education andknowledge. ${ }^{2}$
The male factors were disorders of spermatogenesis $50 \%$,obstruction of the efferent ducts $30 \%$,disorders of sperm motility $15 \%$ and sexual disfunction. ${ }^{3} \mathrm{~A}$ range of assisted reproduction techniques are available to treat the infertile couple and it is important that the appropriate treatment option is offered, such as In vitro fertilization, Donar insemination, Gamete intrafallopian transfer, Zygote intrafallopian transfer, storage or gametes of embryos, and ovulationinduction. ${ }^{4}$

\section{STATEMENT OF THE PROBLEM:}

A descriptive study to assess the contributing factors of infertility and treatment modalities used among the infertile couples in Srishti hospital at Puducherry. 


\section{OBJECTIVES:}

- To identify the types of infertility among the infertile couples attending Out Patient Department, Srishti hospital, Puducherry.

- To find out the availability of various type of treatment modalities used among infertile couples in Srishti hospital, Puducherry.

- To find out the association between type of infertility among infertile couples with selected demographicvariables.

- To find out the association between contributing factors of infertility among infertile couples with selected demographic variables.

\section{RESEARCH METHODOLOGY:}

Descriptive research design was adopted for the study. The study was conducted in Srishti hospital at Puducherry. The population was infertile couples who are getting treatment in Srishti hospital. Infertile couples and those who fulfill the inclusion criteria were selected as sample by convenient sampling technique. The Data was Collected after obtaining formal permission from the director Srishti Hospital and the study participants. After explanation of the purposes of the study, the structured questionnaire was provided to the samples and the time limit of 30 minutes was given for the completion of questionnaire.

Frequency and percentage distribution of type of Infertility among the infertile couples in SrishtiHospital.

\begin{tabular}{|l|c|c|c|}
\hline S.NO & $\begin{array}{c}\text { TYPE OF } \\
\text { INFERTILITY }\end{array}$ & $\begin{array}{c}\text { FREQUEN- } \\
\text { CY }\end{array}$ & $\begin{array}{c}\text { PERCENTAGE } \\
(\%)\end{array}$ \\
\hline 1. & Primary & 29 & 83 \\
\hline 2. & Secondary & 6 & 17 \\
\hline
\end{tabular}

\section{MAJOR FINDINGS OF THE STUDY:}

- With regard to age of infertile couples $15(43 \%)$ belonged to the age group of 20 30 yrs, regarding gender $31(89 \%)$ were females, out of 35 samples 16 (45\%) were married above 6 years of duration , 25 (71\%) were having regular menstrual cycle, regarding the $\mathrm{Rh}$ type 25 (71\%) were $\mathrm{Rh}$ negative blood group, regarding weight 15 (43\%) were between $45-60 \mathrm{~kg}$, majority of the women $20(57 \%)$ had hemoglobin level of $8.6-11 \mathrm{gm} \%$.

- With respect to types of infertility, out of 35 infertile couples 29(83\%) had primary type of infertility and 6 (17\%) had secondary type ofinfertility.

- The contributing factors of infertile couples were Endocrine disorder 14 (40\%), Systemic diseases 1 (3\%), Obstruction or absence of seminal duct 14 (40\%),Sperm causes $1(3 \%)$ and others 5 (14\%).

- The treatment modalities used among 35 infertile couples were invitro fertilization $26(74 \%)$, embryo cryo preservation 2(6\%), intra uterine insemination 5 (14\%), intra cytoplasmic injection2(\%).

- Association between different type of infertility among infertile couples with selected demographic variables revealed that type of marriage, age, residence, duration of marriage found to be Significant at the level of $\mathrm{P}<0.05$.

- The Association between contributing factors among infertile couples with selected demographic variables revealed that Age, Hemoglobin ,Height, Duration of marriage found to be significant at the level of $\mathrm{P}<0.05$.

\section{Limitations:}

- The study was limited to infertile couples in Shrishti hospital atPuducherry.

- The study period was limited to one week 


\section{CONCLUSION:}

The study concluded that the majority of women were infertile than male. Out of 35 samples, 29 had primary type of infertility .Infertility can be treated and cured and there is a great need to improve the awareness regarding the investigations and treatment modalities of infertility.

\section{BIBLIOGRAPHY:}

1. D.C.Dutta, Textbook of Gynaecology, $4^{\text {the }}$ dition , Calcutta: New central Bookagency

(P) Ltd, Page no:212-240

2.LakshmiSeshadri,Essentials

of
3.VG Padubidri,Shirish N DaftaryHowkins and Bourne,Shaw'S Textbook of Gynaecology,14thedition,ElsevierPublication ,Page No 180-198.

4.Myles, Textbook of Midwives, $15^{\text {th }}$ edition ,Elsevier Publication, 2007,Page no :174180

5. AnnammaJacob,A Comprehensive Text book of Midwifery \& Gynecological Nursing,4 th edition, Jaypee Brothers Medical Publishers,Newdelhi,Page No:857866.

\section{The 4 H's That Invalidate a Neuro Exam}

- Hypotension

- Hpoxia

- Hypoglycemia

- Hypothermia 